\title{
Communication
}

\section{Total Synthesis of the Highly N-Methylated Peptides Carmabin A and Dragomabin}

\author{
Baijun Ye ${ }^{1}$, Peng Jiang ${ }^{1}$, Tingrong Zhang ${ }^{1}$, Yuanjun Sun ${ }^{1}$, Xin Hao ${ }^{1}$, Yingjun Cui ${ }^{1}$, \\ Liang Wang ${ }^{1, *}$ and Yue Chen ${ }^{1,2, *}$ \\ 1 The State Key Laboratory of Medicinal Chemical Biology, College of Pharmacy and Tianjin Key Laboratory \\ of Molecular Drug Research, Nankai University, Tianjin 300350, China; yebaijunts@126.com (B.Y.); \\ jiang1921372889@126.com (P.J.); nku2120181185@126.com (T.Z.); sunyuanjun7818@163.com (Y.S.); \\ haoxinbit@126.com (X.H.); cyj10080@126.com (Y.C.) \\ 2 Collaborative Innovation Center of Chemical Science and Engineering, Tianjin 300350, China \\ * $\quad$ Correspondence: lwang@nankai.edu.cn (L.W.); yuechen@nankai.edu.cn (Y.C.); Tel.: +86-22-8535-8387 (Y.C.)
}

Received: 28 August 2018; Accepted: 12 September 2018; Published: 17 September 2018

check for updates

\begin{abstract}
The first total synthesis of carmabin A and dragomabin was achieved at $52.3 \mathrm{mg}$ and $43.8 \mathrm{mg}$ scale, respectively. The synthesis led to determination of the configuration of carmabin A and reassignment of the configuration of dragomabin at the stereogenic centre on the alkyne-bearing fragment.
\end{abstract}

Keywords: total synthesis; stereochemical determination/revision; carmabin A; dragomabin

\section{Introduction}

Secondary metabolites produced by marine microorganisms are a rich source of valuable pharmaceuticals ranging from antimalarial agents to anticancer agents [1-4]. Marine cyanobacteria are widely distributed throughout the world [5] and produce a large number of structurally complex secondary metabolites containing alkynyl groups [6]. Due to their intriguing biological activities, these compounds have attracted the attention of many synthetic chemists [7-13], including us [14]. Carmabin A and dragomabin, two acetylene-containing lipopeptides, were discovered in 1998 [15,16] and 2007 [16] as secondary metabolites of cyanobacterium Lyngbyamajuscula in Panama by Gerwick et al. Structurally characterized with multiple $\mathrm{N}$-methylated amino acids and a lipid chain (Mdya for carmabin A, Moya for dragomabin), carmabin A showed antimalarial activity (4.3 $\mu \mathrm{M})$ towards the W2 chloroquine-resistant malaria strain and inhibitory activity towards mammalian Vero cells. Dragomabin, which has lost a propyl unit compared to carmabin A, showed antimalarial activity $(6.0 \mu \mathrm{M})$ towards the W2 chloroquine-resistant malaria strain but very weak cytotoxicity to Vero cells. Thus, dragomabin possesses significant differential toxicity between parasite and mammalian cells. However, due to the scarceness of carmabin A and dragomabin, the medicinal chemistry as well as the mechanism of action have not been explored.

Without sufficient material, Gerwick et al. could not degrade carmabin A to obtain free Mdya to determine the configuration of the stereogenic centre by comparison with synthetic isomers [16]. They proposed a configuration of $35 S, 37 R$ or $35 R, 37 S$ for the Mdya fragment of carmabin A according to the strong correlations between $\mathrm{H}-35$ and $\mathrm{CH}_{3}-45$ and between $\mathrm{H}-35$ and $\mathrm{CH}_{3}-33$ [16]. The absolute stereochemistry of dragomabin was not clearly elucidated. Gerwick et al. proposed that dragomabin possesses a configuration of $35 \mathrm{~S}$ for the Moya fragment according to the comparison of spectroscopic data between dragomabin and 35S-dragonamide A and 35R-dragonamide A [16].

In addition, the highly $\mathrm{N}$-methylated amino acids of carmabin $\mathrm{A}$ and dragomabin led to two or more discernible conformers, which complicated the determination of absolute configuration (e.g., carmabin A: five conformers with a ratio of 23:6:5:1:1 in DMSO- $d_{6}{ }^{1} \mathrm{H}$ NMR spectrum) [15]. 
Synthetic access to useful quantities of carmabin A and dragomabin has been hampered by their unknown stereochemical configurations and conformers caused by the $\mathrm{N}$-methyl groups, which further undermines investigation of those lipopeptides as potential lead compounds as well as the study of their mechanism of action. Further medicinal research enabled by chemical synthesis of carmabin A and dragomabin may provide new leads for drug discovery. Herein, we report the first total synthesis and absolute stereochemical determination of carmabin A at C35, C37. In addition, we report the first total synthesis of dragomabin with a revision of the stereochemical configuration at C35.

\section{Results}

Scheme 1 illustrates our retrosynthetic analysis. The C-terminal amide of carmabin A and dragomabin could be prepared via amidation of the $C$-terminal methyl esters of compounds 3 and 4. Compounds 3 and 4 were further disconnected into two parts: the Mdya/Moya fragment and protected tetrapeptide 7 . Tetrapeptide 7 could be prepared by repeated condensation reactions of amino acids. The methyl group of Mdya/Moya 5/6 could be stereoselectively installed following the methodology developed by Evans [17-19].
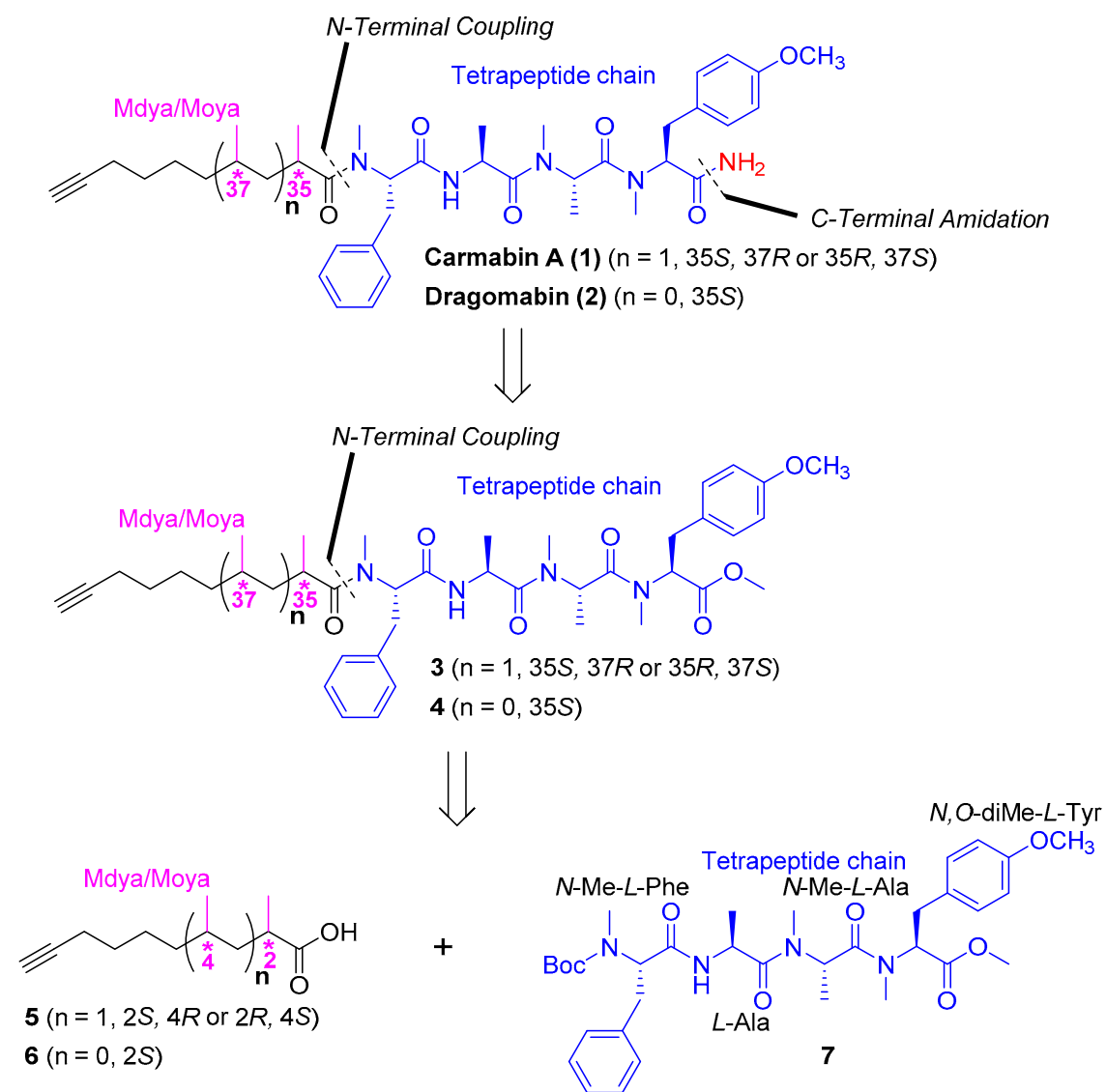

Scheme 1. Retrosynthetic analysis of carmabin A (1) and dragomabin (2).

\subsection{Synthesis of Mdya 5 of Carmabin A}

The forward synthesis started with the synthesis of acid 5 (Scheme 2). Carboxylic acid 8 was prepared according to the literature. By employing the route we previously developed for the synthesis of ent-5 [14], 8 was converted to corresponding alcohol 12 in a four-step sequence involving acyl chlorination, amidation with benzyl-2-oxazolidinone, diastereoselective $\alpha$-methylation, and reduction in $46 \%$ overall yield (four steps). Alcohol 12 was converted to iodide $\mathbf{1 3}$ under Appel reaction conditions [20]. Iodide $\mathbf{1 3}$ was then subjected to asymmetric alkylation with the enolate generated 
from 14 to afford 15 [17] in 66\% yield (d.r. > 20:1 according to ${ }^{1} \mathrm{H}$ NMR), which constructed the $2 S, 4 R$ stereochemistry on the Mdya fragment. Treatment of resulting 15 with $1 \mathrm{~N} \mathrm{HCl}$ led to the hydrolysis of both the TMS group and the amide bond, providing 5 in $61 \%$ yield ( $2.1 \mathrm{~g}$ scale, one batch).
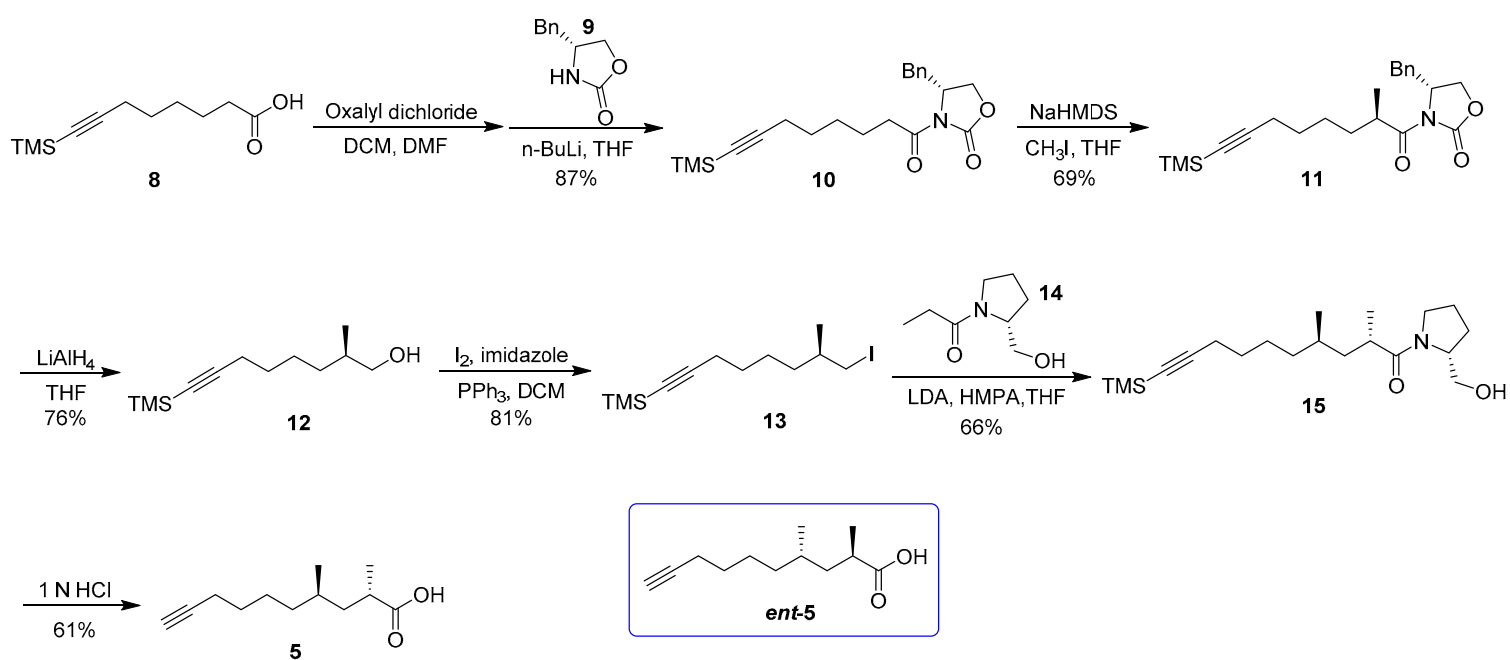

Scheme 2. Synthesis of Mdya 5.

\subsection{Synthesis of Tetrapeptide 7}

Scheme 3 depicts the construction of tetrapeptide 7. Boc deprotection of 16 using TFA followed by condensation with 17 under the conventional coupling conditions (HATU/DIPEA) discovered by Louis A. Carpino [21] produced 18 in $85 \%$ yield. By repeating the condensation under the same conditions, Boc-L-Ala 19 and Boc-N-Me-L-Phe 21 were sequentially introduced, providing protected tetrapeptide 7. The relatively low yield of the condensation can probably be attributed to the steric hindrance imposed by the additional methyl group. Problematic undesired diketopiperazine (DKP) formation $[22,23]$ was not observed during the condensation reaction.
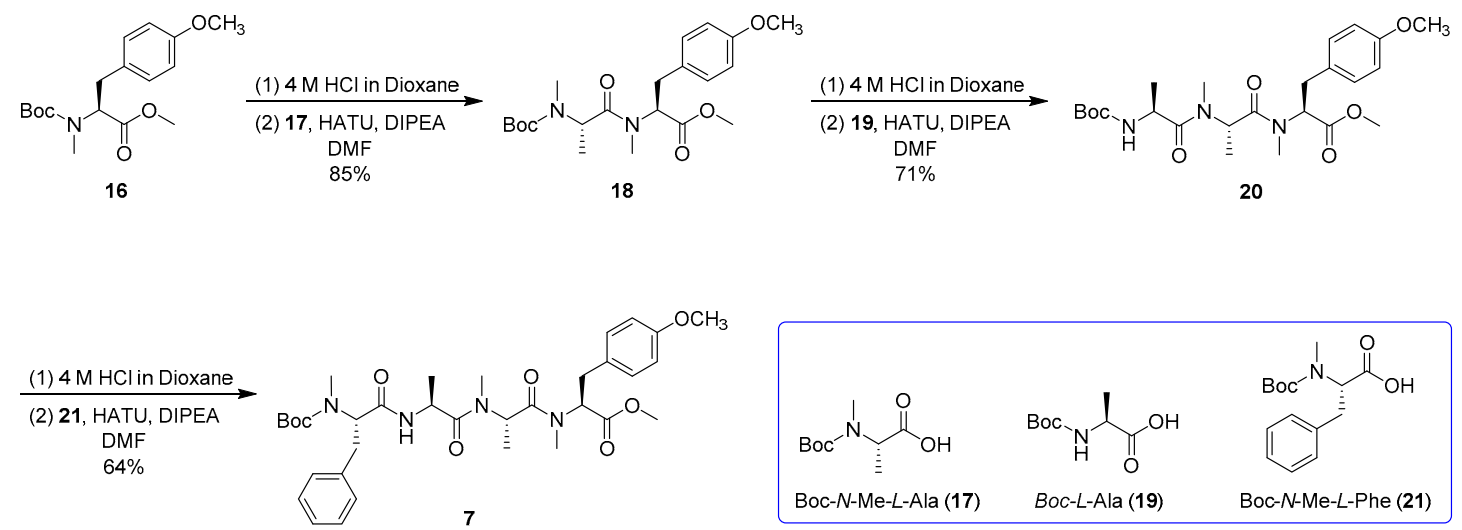

Scheme 3. Synthesis of tetrapeptide 7.

\subsection{Total Synthesis of Carmabin A and Discussion}

With 7, 5, ent-5 in hand, we next aimed at completing the total synthesis of carmabin A and confirming its absolute stereochemistry (Scheme 4). The final steps involved coupling reactions between Boc-deprotected 7 with 5 and with $\boldsymbol{e n t}-\mathbf{5}$ followed by treatment with ammonia to produce 1 and 1a. After deprotection of 7 under $4 \mathrm{M} \mathrm{HCl}$, the resulting intermediate was subjected to coupling reaction directly, while only a trace amount of condensation product was observed. This could be explained by that 7 or Boc-deprotected 7 are unstable under $4 \mathrm{M} \mathrm{HCl}$. By switching $4 \mathrm{M} \mathrm{HCl}$ for $10 \%$ TFA, the coupling reaction proceeded smoothly to provide 3 and $3 a$ in $61 \%$ and $59 \%$ yields, respectively. 
The transformation from 3 to $\mathbf{1}$ was first conducted in anhydrous $\mathrm{NH}_{3}$ solution $(7.0 \mathrm{M}$ in $\mathrm{MeOH})$ at room temperature. With most of starting material left in the reaction system, only $10 \%$ yield of 1 was observed. Elevating the temperature to $40{ }^{\circ} \mathrm{C}$ improved the yield to $40 \%$. When the reaction was transferred to a sealed tube in $60{ }^{\circ} \mathrm{C}, 1$ and 1 a were obtained in $67 \%$ and $64 \%$ yield, respectively. After careful comparison, the spectroscopic data of synthetic 1 were consistent within the margin of error (0.02 ppm for ${ }^{1} \mathrm{H}$ NMR and $0.2 \mathrm{ppm}$ for $\left.{ }^{13} \mathrm{C} \mathrm{NMR}\right)$ for the data originally reported for natural 1. The NMR data of synthetic 1a did not match the data of natural 1. Consequently, the absolute configuration of carmabin A was established as shown in $\mathbf{1}$.

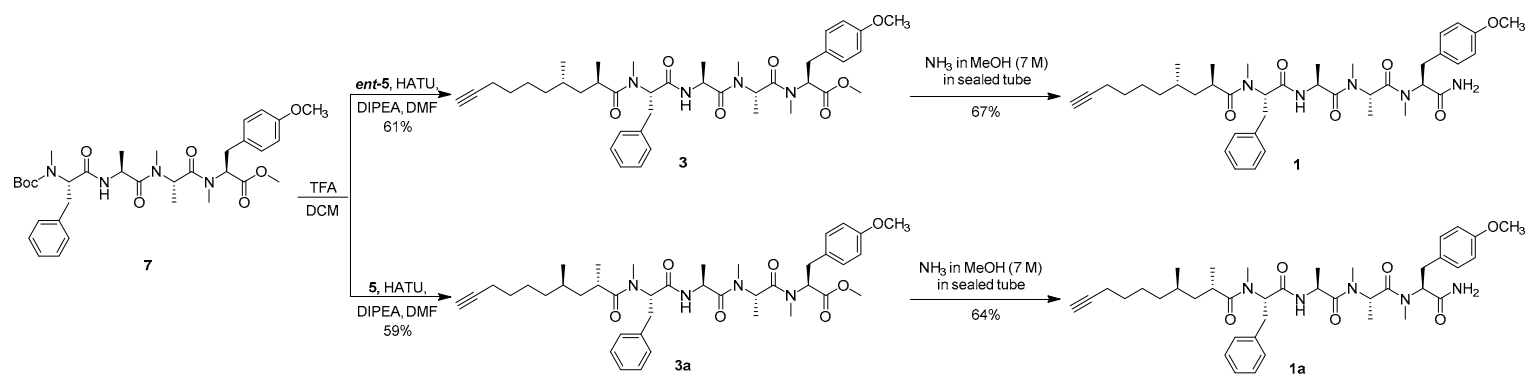

Scheme 4. Total synthesis of carmabin A (1).

\subsection{Synthesis of Moya 6 of Dragomabin}

Next, we turned our attention to dragomabin. The Moya 6 fragment of dragomabin was obtained from ent-11 via deprotection of TMS with TFA followed by removal of the chiral auxiliary (Scheme 5).

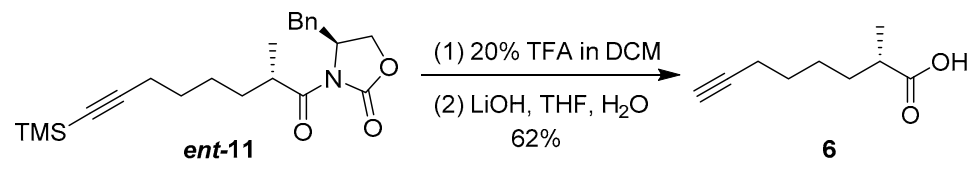

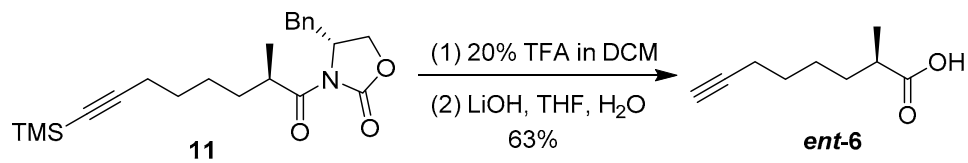

Scheme 5. Synthesis of Moya 6 and ent-6.

\subsection{Total Synthesis of Dragomabin and Discussion}

After deprotection of 7 under $4 \mathrm{M} \mathrm{HCl}$, the resulting intermediate was subjected to a coupling reaction, which proceeded smoothly to provide 4 in $55 \%$ yield. Amidation of 4 with anhydrous $\mathrm{NH}_{3}$ solution afforded compound $\mathbf{2}$ in $61 \%$ yield (Scheme 6). Compound $\mathbf{2}$ was prepared with the same stereochemistry as that reported in the isolation paper. However, neither the ${ }^{1} \mathrm{HNMR}$ data nor the optical rotation data are consistent with the reported values. The main concern regarding the true structure was the configuration at C35. By employing the same procedure described above, ent-6 was obtained from $\mathbf{1 1}$ and then subjected to condensation with tetrapeptide $\mathbf{7}$ to give $\mathbf{2 a}$. It was indeed found that the data for $\mathbf{2} \mathbf{a}$ were consistent with those of natural dragomabin. Thus, the correct structure for dragomabin was revised as shown in 2a. As dragomabin and dragonamide differ in the stereochemistry on the Moya fragment, it appears that the stereochemistry on the alkyne fragment in these lipopeptides is variable and correlation with other natural products is not reliable. 


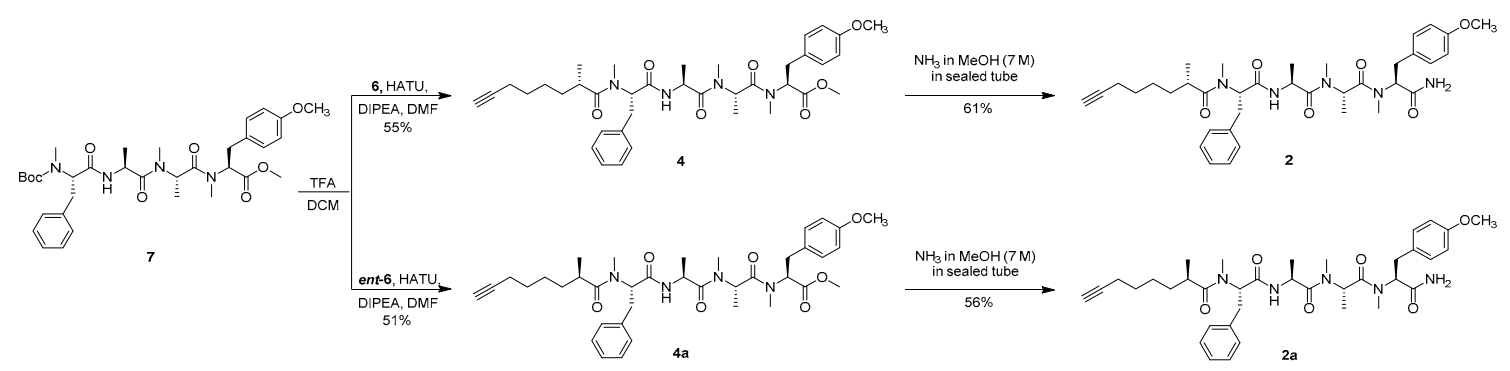

Scheme 6. Total synthesis of dragomabin (2).

\section{Materials and Methods}

\subsection{General Information}

Reagents were purchased from commercial suppliers and used without purification unless otherwise stated: hexamethylphosphoric triamide (HMPA), ethyl acetate (EtOAc), N,N-dimethylformamide (DMF), lithium diisopropylamide (LDA), dichloromethane (DCM), hydrochloric acid ( $\mathrm{HCl})$, trifluoroacetic acid (TFA), 1-(Bis(dimethylamino)methylene)-1H-1,2,3-triazolo(4,5-b)pyridinium 3-oxid hexafluorophosphate (HATU), and $N, N$-Diisopropy-lethylamine (DIPEA).

All reactions were carried out under an argon atmosphere with dry solvents under anhydrous conditions, unless otherwise noted. Tetrahydrofuran (THF) was distilled immediately before use from sodium-benzophenone ketyl. Diisopropylamine was distilled from calcium hydride. Solvents for chromatography were used as supplied by Tianjin Reagents Chemical (Tianjin, China). Reactions were monitored by thin-layer chromatography (TLC) carried out on silica gel plates, using UV light as the visualizing agent and aqueous phosphomolybdic acid or basic aqueous potassium permanganate as the developing agent. A 200-300 mesh silica gel was used for column chromatography.

Optical rotations were recorded on an Insmark IP 120 digital polarimeter (Insmark, Shanghai, China). IR spectra were recorded on a Bruker Tensor 27 instrument (Ettlingen, Germany). Only the strongest and/or most structurally important absorptions of IR spectra were reported in wavenumbers $\left(\mathrm{cm}^{-1}\right) \cdot{ }^{1} \mathrm{H} \mathrm{NMR},{ }^{13} \mathrm{C} \mathrm{NMR}$, and 2D NMR were recorded on Bruker AV 400 and calibrated by using internal references and solvent signals $\mathrm{CDCl}_{3}\left(\delta_{\mathrm{H}}=7.26 \mathrm{ppm}, \delta_{\mathrm{C}}=77.16 \mathrm{ppm}\right)$, unless otherwise noted. ${ }^{1} \mathrm{H}$ NMR data are reported as follows: chemical shift, multiplicity ( $\mathrm{s}=$ singlet, $\mathrm{d}=\mathrm{doublet}$, $\mathrm{t}=$ triplet, $\mathrm{q}=$ quartet, $\mathrm{p}=$ quintet, $\mathrm{br}=$ broad, $\mathrm{m}=$ multiplet), coupling constants and integration. High-resolution mass spectra (HRMS) were detected on an IonSpec FT-ICR mass spectrometer by Varian 7.0T FTMS (Kuala Lumpur, Malaysia).

\subsection{Chemistry}

(2S,4R)-2,4-Dimethyldec-9-ynoic acid (5) was obtained following the procedure for the preparation of compound (2R,4S)-2,4-dimethyldec-9-ynoic acid(ent-5) [14].

(R)-4-Benzyl-3-(8-(trimethylsilyl)oct-7-ynoyl)oxazolidin-2-one (10) Yield: 87\%; $[\alpha]_{\mathrm{D}}^{21}-39.5\left(c 1.0, \mathrm{CHCl}_{3}\right)$; IR (KBr) $v_{\max } 2959,2932,2172,1796,1701,1244,1056,759,644 \mathrm{~cm}^{-1} ;{ }^{1} \mathrm{H}$ NMR $\left(400 \mathrm{MHz}, \mathrm{CDCl}_{3}\right) \delta$ 7.35-7.20 (m, 5H), 4.70-4.64 (m, 1H), 4.22-4.16 (m, 2H), $3.30(\mathrm{dd}, J=13.3,3.1 \mathrm{~Hz}, 1 \mathrm{H}), 3.02-2.85(\mathrm{~m}, 2 \mathrm{H})$, $2.76(\mathrm{dd}, J=13.3,9.7 \mathrm{~Hz}, 1 \mathrm{H}), 2.25(\mathrm{t}, J=7.0 \mathrm{~Hz}, 2 \mathrm{H}), 1.76-1.67(\mathrm{~m}, 2 \mathrm{H}), 1.60-1.43(\mathrm{~m}, 4 \mathrm{H}), 0.14(\mathrm{~s}, 9 \mathrm{H})$; ${ }^{13} \mathrm{C}$ NMR $\left(100 \mathrm{MHz} \mathrm{CDCl}_{3}\right) \delta 173.3,153.6,135.4,129.5,129.1,127.5,107.4,84.7,66.3,55.3,38.1,35.5$, 28.5, 28.4, 23.9, 19.8, 0.3; HRESIMS $m / z$ 394.1815 [M + Na] ${ }^{+}$(calcd. for $\mathrm{C}_{21} \mathrm{H}_{29} \mathrm{NNaO}_{3} \mathrm{Si}^{+}, 394.1809$ ).

(R)-4-Benzyl-3-((R)-2-methyl-8-(trimethylsilyl)oct-7-ynoyl)oxazolidin-2-one (11) Yield: $69 \% ;[\alpha]_{\mathrm{D}}^{20}-52.3$ (c 1.0, $\left.\mathrm{CHCl}_{3}\right)$; IR (KBr) $v_{\max } 2939,2862,2174,1783,1699,1211,761,640 \mathrm{~cm}^{-1}$; ${ }^{1} \mathrm{H} \mathrm{NMR}(400 \mathrm{MHz}$, $\left.\mathrm{CDCl}_{3}\right) \delta 7.35-7.20(\mathrm{~m}, 5 \mathrm{H}), 4.67(\mathrm{qd}, J=6.6,2.8 \mathrm{~Hz}, 1 \mathrm{H}), 4.23-4.14(\mathrm{~m}, 2 \mathrm{H}), 3.73-3.67(\mathrm{~m}, 1 \mathrm{H}), 3.27(\mathrm{dd}$, $J=13.3,2.9 \mathrm{~Hz}, 1 \mathrm{H}), 2.77(\mathrm{dd}, J=13.3,9.6 \mathrm{~Hz}, 1 \mathrm{H}), 2.22(\mathrm{t}, J=7.0 \mathrm{~Hz}, 2 \mathrm{H}), 1.77-1.75(\mathrm{~m}, 1 \mathrm{H}), 1.53-1.35$ $(\mathrm{m}, 5 \mathrm{H}), 1.23(\mathrm{~d}, J=6.8 \mathrm{~Hz}, 3 \mathrm{H}), 0.14(\mathrm{~s}, 9 \mathrm{H}) ;{ }^{13} \mathrm{C} \mathrm{NMR}\left(100 \mathrm{MHz}, \mathrm{CDCl}_{3}\right) \delta 177.3,153.2,135.5,129.6$, 
129.1, 127.5, 107.4, 84.7, 66.2, 55.5, 38.1, 37.8, 32.9, 28.7, 26.5, 19.9, 17.4, 0.3; HRESIMS $m / z$ 408.1969 [M + $\mathrm{Na}]^{+}$(calcd. for $\mathrm{C}_{22} \mathrm{H}_{31} \mathrm{NNaO}_{3} \mathrm{Si}^{+}$, 408.1965).

(R)-2-Methyl-8-(trimethylsilyl)oct-7-yn-1-ol (12) Yield: 76\%; $[\alpha]_{\mathrm{D}}^{20}+6.3\left(\right.$ c 1.0, $\left.\mathrm{CHCl}_{3}\right)$; IR (KBr) $v_{\max } 3372$, 2958, 2937, 2175, 1250, 1044, 760, $640 \mathrm{~cm}^{-1} ;{ }^{1} \mathrm{H}$ NMR (400 MHz, $\left.\mathrm{CDCl}_{3}\right) \delta 3.54-3.40(\mathrm{~m}, 2 \mathrm{H}), 2.23(\mathrm{t}$, $J=6.9 \mathrm{~Hz}, 2 \mathrm{H}), 1.67-1.60(\mathrm{~m}, 1 \mathrm{H}), 1.55-1.35(\mathrm{~m}, 5 \mathrm{H}), 1.28(\mathrm{t}, J=5.5 \mathrm{~Hz}, 1 \mathrm{H}), 1.19-1.06(\mathrm{~m}, 1 \mathrm{H}), 0.92(\mathrm{~d}$, $J=6.7 \mathrm{~Hz}, 3 \mathrm{H}), 0.14(\mathrm{~s}, 9 \mathrm{H}) ;{ }^{13} \mathrm{C} \mathrm{NMR}\left(100 \mathrm{MHz}, \mathrm{CDCl}_{3}\right) \delta 107.7,84.6,68.4,35.8,32.6,28.9,26.2,19.9$, 16.6, 0.3 ; compound 12 was not observed by HRESIMS analysis due to complete fragmentation.

(R)-(8-Iodo-7-methyloct-1-yn-1-yl)trimethylsilane (13) Yield: 81\%; $[\alpha]_{\mathrm{D}}^{21}-2.8\left(c 1.0, \mathrm{CHCl}_{3}\right)$; IR (KBr) $v_{\max }$ 2959, 2935, 2174, 1249, 1195, 760, $640 \mathrm{~cm}^{-1} ;{ }^{1} \mathrm{H}$ NMR $\left(400 \mathrm{MHz}, \mathrm{CDCl}_{3}\right) \delta 3.25-3.13(\mathrm{~m}, 2 \mathrm{H}), 2.23(\mathrm{t}$, $J=6.9 \mathrm{~Hz}, 2 \mathrm{H}), 1.53-1.32(\mathrm{~m}, 6 \mathrm{H}), 1.28-1.18(\mathrm{~m}, 1 \mathrm{H}), 0.98(\mathrm{~d}, J=6.4 \mathrm{~Hz}, 3 \mathrm{H}), 0.15(\mathrm{~s}, 9 \mathrm{H}) ;{ }^{13} \mathrm{C}$ NMR $(100$ $\left.\mathrm{MHz}, \mathrm{CDCl}_{3}\right) \delta 107.5,84.8,36.0,34.7,28.6,26.1,20.7,19.9,17.8,0.3$; compound 13 was not observed by HRESIMS analysis due to complete fragmentation.

(2S,4R)-1-((R)-2-(Hydroxymethyl)pyrrolidin-1-yl)-2,4-dimethyl-10-(trimethylsilyl)dec-9-yn-1-one (15) Yield: $66 \% ;[\alpha]_{\mathrm{D}}^{21}+30.2\left(c 1.0, \mathrm{CHCl}_{3}\right) ; \mathrm{IR}(\mathrm{KBr}) v_{\max } 3431,2959,2935,2174,1620,1463,1249,1052,759$, $640 \mathrm{~cm}^{-1} ;{ }^{1} \mathrm{H}$ NMR $\left(400 \mathrm{MHz}, \mathrm{CDCl}_{3}\right) \delta 5.21(\mathrm{dd}, J=7.7,2.1 \mathrm{~Hz}, 1 \mathrm{H}), 4.23(\mathrm{dd}, J=13.7,5.8 \mathrm{~Hz}, 1 \mathrm{H})$, 3.69-3.46 (m, 4H), $2.62(\mathrm{dd}, J=13.4,6.7 \mathrm{~Hz}, 1 \mathrm{H}), 2.20(\mathrm{t}, J=6.9 \mathrm{~Hz}, 2 \mathrm{H}), 2.07-1.84(\mathrm{~m}, 3 \mathrm{H}), 1.59-1.23(\mathrm{~m}$, $10 \mathrm{H}), 1.12(\mathrm{~d}, J=6.7 \mathrm{~Hz}, 3 \mathrm{H}), 0.86(\mathrm{~d}, J=5.8 \mathrm{~Hz}, 3 \mathrm{H}), 0.14(\mathrm{~s}, 9 \mathrm{H}) ;{ }^{13} \mathrm{C} \mathrm{NMR}\left(100 \mathrm{MHz}, \mathrm{CDCl}_{3}\right) \delta 178.7$, 107.6, 84.5, 68.0, 61.3, 48.0, 40.7, 36.9, 35.9, 30.5, 28.9, 28.5, 26.1, 24.7, 19.9, 19.5, 17.4, 0.3; HRESIMS $m / z$ $374.2490[\mathrm{M}+\mathrm{Na}]^{+}$(calcd. for $\mathrm{C}_{20} \mathrm{H}_{37} \mathrm{NNaO}_{2} \mathrm{Si}^{+}, 374.2486$ ).

(2S,4R)-2,4-Dimethyldec-9-ynoic acid (5) Yield: 61\%; $[\alpha]_{\mathrm{D}}^{22}+5.6\left(c\right.$ 1.0, $\left.\mathrm{CHCl}_{3}\right)$; IR (KBr) $v_{\max } 3309,2937$, 2862, 2118, 1706, 1292, $633 \mathrm{~cm}^{-1}$; ${ }^{1} \mathrm{H}$ NMR $\left(400 \mathrm{MHz}, \mathrm{CDCl}_{3}\right) \delta 2.59-2.50(\mathrm{~m}, 1 \mathrm{H}), 2.19(\mathrm{td}, J=6.9$, $2.4 \mathrm{~Hz}, 2 \mathrm{H}), 1.94(\mathrm{t}, J=2.4 \mathrm{~Hz}, 1 \mathrm{H}), 1.59-1.31(\mathrm{~m}, 9 \mathrm{H}), 1.16(\mathrm{~d}, J=6.9 \mathrm{~Hz}, 3 \mathrm{H}), 0.87(\mathrm{~d}, J=6.2 \mathrm{~Hz}, 3 \mathrm{H})$; ${ }^{13} \mathrm{C}$ NMR $\left(100 \mathrm{MHz}, \mathrm{CDCl}_{3}\right) \delta 182.7,84.8,68.3,40.9,37.1,36.5,30.5,28.8,26.1,19.4,18.5,17.0$; HRESIMS $m / z 195.1388[\mathrm{M}-\mathrm{H}]^{-}$(calcd. for $\left.\mathrm{C}_{12} \mathrm{H}_{19} \mathrm{O}^{-}, 195.1391\right)$; the optical rotation of ent $-5\left([\alpha]_{\mathrm{D}}^{20}-5.8(c 1.0\right.$, $\left.\mathrm{CHCl}_{3}\right)$ ).

Boc-N-Me-L-Ala-N,O-diMe-L-Tyr (18) Compound 16 (30.0 g, $92.8 \mathrm{mmol})$ was dissolved in $4.0 \mathrm{M} \mathrm{HCl}$ in dioxane $(150 \mathrm{~mL})$. After the mixture had been stirred for $3 \mathrm{~h}$ at room temperature, the whole mixture was concentrated to afford an $\mathrm{HCl}$ salt as a white solid and used directly for the next step. To the solution of the $\mathrm{HCl}$ salt, compound $17(37.7 \mathrm{~g}, 185 \mathrm{mmol})$, and HATU $(70.3 \mathrm{~g}, 185 \mathrm{mmol})$ in DMF $(150 \mathrm{~mL})$ was added DIPEA $(48.0 \mathrm{~g}, 371 \mathrm{mmol})$ at $0{ }^{\circ} \mathrm{C}$ under argon, and then the mixture was warmed to room temperature and stirred overnight. After being diluted with EtOAc $(800 \mathrm{~mL})$, the whole mixture was washed with $1 \% \mathrm{HCl}(3 \times 150 \mathrm{~mL}), 5 \%$ aqueous $\mathrm{NaHCO}_{3}(3 \times 150 \mathrm{~mL})$, and brine $(3 \times 150 \mathrm{~mL})$, and the organic layer was dried over $\mathrm{Na}_{2} \mathrm{SO}_{4}$ and filtered. The filtrate was concentrated and purified by silica gel column chromatography (10/1 to 3/1 petroleum ether/EtOAc) to afford compound $18(32.2 \mathrm{~g}, 85 \%)$ as a colorless oil: $[\alpha]_{\mathrm{D}}^{24}-121.2\left(c 1.0, \mathrm{CHCl}_{3}\right)$; IR $(\mathrm{KBr}) v_{\max } 2978,1745,1657$, $1515,1249,833,561 \mathrm{~cm}^{-1} ;{ }^{1} \mathrm{H}$ NMR $\left(400 \mathrm{MHz}, \mathrm{CDCl}_{3}\right)$ mixture of rotamers $\delta 7.14,7.09(\mathrm{~d}, J=8.3 \mathrm{~Hz}$, $2 \mathrm{H}), 7.09(\mathrm{~d}, J=8.3 \mathrm{~Hz}, 1 \mathrm{H}), 6.84,6.80(\mathrm{~d}, J=8.5 \mathrm{~Hz}, 2 \mathrm{H}), 5.37,5.12,5.05(\mathrm{dd}, J=11.4,4.8 \mathrm{~Hz}, 1 \mathrm{H})$, $5.02,4.80,4.70,4.63,4.33(\mathrm{q}, J=6.6 \mathrm{~Hz}, 1 \mathrm{H}), 3.76(\mathrm{~s}, 3 \mathrm{H}), 3.73(\mathrm{~s}, 3 \mathrm{H}), 3.35-3.28(\mathrm{~m}, 1 \mathrm{H}), 3.03-2.93(\mathrm{~m}$, $1 \mathrm{H}), 2.85,2.84,2.80(\mathrm{~s}, 3 \mathrm{H}), 2.58,2.55,2.23,2.19(\mathrm{~s}, 3 \mathrm{H}), 1.44,1.43,1.42(\mathrm{~s}, 9 \mathrm{H}), 1.19,1.09,0.97,0.90(\mathrm{~d}$, $J=6.7 \mathrm{~Hz}, 3 \mathrm{H}) ;{ }^{13} \mathrm{C} \mathrm{NMR}\left(100 \mathrm{MHz}, \mathrm{CDCl}_{3}\right)$ mixture of rotamers $\delta 171.9,171.7,171.3,171.1,158.7$, 158.6, 155.3, 155.2, 130.1, 130.0, 129.8, 129.2, 128.5, 114.3, 114.1, 80.1, 80.0, 61.0, 60.6, 59.5, 58.6, 55.4, 52.5, 52.4, 51.7, 50.8, 49.5, 34.6, 33.8, 32.9, 31.9, 30.0, 29.8, 28.9, 28.6, 28.4, 28.1, 14.4; HRESIMS m/z 431.2155 $[\mathrm{M}+\mathrm{Na}]^{+}$(calcd. for $\mathrm{C}_{21} \mathrm{H}_{32} \mathrm{~N}_{2} \mathrm{NaO}_{6}{ }^{+}, 431.2153$ ).

Boc-L-Ala-N-Me-L-Ala-N,O-diMe-L-Tyr (20) Compound 18 (31.0 g, $75.9 \mathrm{mmol}$ ) was dissolved in $4.0 \mathrm{M}$ $\mathrm{HCl}$ in dioxane $(150 \mathrm{~mL})$. After the mixture had been stirred for $3 \mathrm{~h}$ at room temperature, the whole mixture was concentrated to afford an $\mathrm{HCl}$ salt as a white solid and used directly for the next step. To the solution of the $\mathrm{HCl}$ salt, compound 19 ( $37.7 \mathrm{~g}, 152 \mathrm{mmol})$, and HATU $(57.7 \mathrm{~g}, 152 \mathrm{mmol})$ in DMF $(150 \mathrm{~mL})$ was added DIPEA $(39.2 \mathrm{~g}, 303 \mathrm{mmol})$ at $0{ }^{\circ} \mathrm{C}$ under argon, and then the mixture was warmed 
to room temperature and stirred overnight. After being diluted with EtOAc $(800 \mathrm{~mL})$, the whole mixture was washed with $1 \% \mathrm{HCl}(3 \times 150 \mathrm{~mL}), 5 \%$ aqueous $\mathrm{NaHCO}_{3}(3 \times 150 \mathrm{~mL})$, and brine $(3 \times 150 \mathrm{~mL})$, and the organic layer was dried over $\mathrm{Na}_{2} \mathrm{SO}_{4}$ and filtered. The filtrate was concentrated and purified by silica gel column chromatography ( $5 / 1$ to $1 / 1$ petroleum ether/EtOAc) to afford compound $20(25.8 \mathrm{~g}, 71 \%)$ as a colorless oil: $[\alpha]_{\mathrm{D}}^{24}-93.4\left(c 1.0, \mathrm{CHCl}_{3}\right)$; IR $(\mathrm{KBr}) v_{\max } 3445,2981$, $1743,1637,1516,1249,1172,614,556 \mathrm{~cm}^{-1} ;{ }^{1} \mathrm{H}$ NMR $\left(400 \mathrm{MHz}, \mathrm{CDCl}_{3}\right)$ mixture of rotamers $\delta 7.09(\mathrm{~d}$, $J=8.5 \mathrm{~Hz}, 1 \mathrm{H}), 6.79(\mathrm{~d}, J=8.5 \mathrm{~Hz}, 1 \mathrm{H}), 5.47-5.33(\mathrm{~m}, 2 \mathrm{H}), 4.85-4.37(\mathrm{~m}, 1 \mathrm{H}), 3.77,3.75(\mathrm{~s}, 3 \mathrm{H}), 3.74,3.71$ (s, 3H), 3.34, 3.26 (dd, J = 14.8, $4.9 \mathrm{~Hz}, 1 \mathrm{H}), 2.97-2.88(\mathrm{~m}, 1 \mathrm{H}), 2.92,2.85,2.71(\mathrm{~s}, 3 \mathrm{H}), 2.83,2.77,2.28$ $(\mathrm{s}, 3 \mathrm{H}), 1.41(\mathrm{~s}, 9 \mathrm{H}), 1.27,1.18,1.11,0.81(\mathrm{~d}, J=6.7 \mathrm{~Hz}, 1 \mathrm{H}) ;{ }^{13} \mathrm{C} \mathrm{NMR}\left(100 \mathrm{MHz}, \mathrm{CDCl}_{3}\right)$ mixture of rotamers $\delta 172.3,171.3,171.1,170.7,158.8,155.1,130.3,129.9,129.7,128.8,128.4,114.3,114.2,114.1,79.8$, $58.2,58.1,55.4,55.36,52.6,52.5,49.7,44.0,46.6,34.5,33.8,31.9,31.8,30.3,30.1,29.7,29.2,28.5,19.0,18.8$, 14.1; HRESIMS $m / z 502.2528[\mathrm{M}+\mathrm{Na}]^{+}$(calcd. for $\mathrm{C}_{24} \mathrm{H}_{37} \mathrm{~N}_{3} \mathrm{NaO}_{7}{ }^{+}$, 502.2524).

Boc-N-Me-L-Phe-L-Ala-N-Me-L-Ala-N,O-diMe-L-Tyr (7) Compound 20 (25.0 g, $52.1 \mathrm{mmol})$ was dissolved in $4.0 \mathrm{M} \mathrm{HCl}$ in dioxane $(125 \mathrm{~mL})$. After the mixture had been stirred for $3 \mathrm{~h}$ at room temperature, the whole mixture was concentrated to afford an $\mathrm{HCl}$ salt as a white solid and used directly for the next step. To the solution of the $\mathrm{HCl}$ salt, compound 21 (29.1 g, $104 \mathrm{mmol})$, and HATU (39.6 g, $104 \mathrm{mmol})$ in DMF $(125 \mathrm{~mL})$ was added DIPEA $(26.9 \mathrm{~g}, 208 \mathrm{mmol})$ at $0{ }^{\circ} \mathrm{C}$ under argon, and then the mixture was warmed to room temperature and stirred overnight. After being diluted with EtOAc $(600 \mathrm{~mL})$, the whole mixture was washed with $1 \% \mathrm{HCl}(3 \times 120 \mathrm{~mL}), 5 \%$ aqueous $\mathrm{NaHCO}_{3}(3 \times 120 \mathrm{~mL})$, and brine $(3 \times 120 \mathrm{~mL})$, and the organic layer was dried over $\mathrm{Na}_{2} \mathrm{SO}_{4}$ and filtered. The filtrate was concentrated and purified by silica gel column chromatography ( $2 / 1$ to $1 / 2$ petroleum ether/EtOAc) to afford compound $7(21.3 \mathrm{~g}, 64 \%)$ as a colorless oil: $[\alpha]_{\mathrm{D}}^{24}-100.6\left(c 1.0, \mathrm{CHCl}_{3}\right)$; IR $(\mathrm{KBr}) v_{\max } 3402$, 2924, 1744, 1644, 1515, 1248, 1174, 615, $556 \mathrm{~cm}^{-1} ;{ }^{1} \mathrm{H}$ NMR $\left(400 \mathrm{MHz}, \mathrm{CDCl}_{3}\right)$ mixture of rotamers $\delta$ 7.27-7.15 (m, 5H), 7.14, $7.12(\mathrm{~d}, J=8.8 \mathrm{~Hz}, 2 \mathrm{H}), 6.96(\mathrm{br}, 1 \mathrm{H}), 6.85,6.81(\mathrm{~d}, J=8.6 \mathrm{~Hz}, 2 \mathrm{H}), 5.40,4.82(\mathrm{~m}$, $1 \mathrm{H}), 5.39-5.31(\mathrm{~m}, 1 \mathrm{H}), 4.81-4.64(\mathrm{~m}, 2 \mathrm{H}), 3.77(\mathrm{~s}, 3 \mathrm{H}), 3.75,3.72(\mathrm{~s}, 3 \mathrm{H}), 3.42-3.26(\mathrm{~m}, 2 \mathrm{H}), 3.00-2.89$ $(\mathrm{m}, 2 \mathrm{H}), 2.86,2.75,2.72(\mathrm{~s}, 3 \mathrm{H}), 2.72,2.32(\mathrm{~s}, 3 \mathrm{H}), 1.46,1.37,1.32(\mathrm{~s}, 9 \mathrm{H}), 1.25,1.14(\mathrm{~d}, J=6.8 \mathrm{~Hz}, 3 \mathrm{H})$, $1.19,0.81(\mathrm{~d}, J=6.8 \mathrm{~Hz}, 3 \mathrm{H}) ;{ }^{13} \mathrm{C}$ NMR $\left(100 \mathrm{MHz}, \mathrm{CDCl}_{3}\right)$ mixture of rotamers $\delta 171.7,171.7,171.6$, $171.3,171.2,171.1,158.9,158.8,130.3,129.9,129.2,128.9,128.6,126.6,114.4,114.2,58.4,55.5,52.5,49.7$, 48.1, 45.7, 34.3, 33.8, 32.0, 29.7, 29.2, 28.3, 18.4, 14.2, 14.1; HRESIMS $m / z 663.3368$ [M + Na] ${ }^{+}$(calcd. for $\mathrm{C}_{34} \mathrm{H}_{48} \mathrm{~N}_{4} \mathrm{NaO}_{8}{ }^{+}$, 663.3364).

Methyl (2S,5S,8S,11S,14R,16S)-11-benzyl-2-(4-methoxybenzyl)-3,5,6,8,12,14,16-heptamethyl-4,7,10,13tetraoxo-3,6,9,12-tetraazadocos-21-ynoate (3) To the solution of compound 7 (200 mg, $0.312 \mathrm{mmol}$ ) in DCM $(1.8 \mathrm{~mL})$ was added TFA $(0.2 \mathrm{~mL})$. After the mixture had been stirred for $6 \mathrm{~h}$ at room temperature, toluene $(2 \mathrm{~mL})$ was added and then the whole mixture was concentrated under reduced pressure. The residue was dissolved with water $(3 \mathrm{~mL})$ and extracted with petroleum ether $(3 \times 1 \mathrm{~mL})$. The aqueous phase was adjusted to $\mathrm{pH} 8-9$ with $\mathrm{Na}_{2} \mathrm{CO}_{3}$ and extracted with $\mathrm{DCM}(3 \times 10 \mathrm{~mL})$, and the combined organic layer was dried over $\mathrm{Na}_{2} \mathrm{SO}_{4}$ and filtered. The filtrate was concentrated to afford a free amine as a colorless oil and used directly for the next step. To the solution of the free amine, ent 5 (122 mg, $0.622 \mathrm{mmol})$, and HATU ( $237 \mathrm{mg}, 0.624 \mathrm{mmol})$ in DMF ( $1 \mathrm{~mL})$ was added DIPEA $(84.7 \mathrm{mg}, 0.655 \mathrm{mmol})$ at $0{ }^{\circ} \mathrm{C}$ under argon, and then the mixture was warmed to room temperature and stirred overnight. After being diluted with EtOAc $(10 \mathrm{~mL})$, the whole mixture was washed with $1 \% \mathrm{HCl}(3 \times 2 \mathrm{~mL}), 5 \%$ aqueous $\mathrm{NaHCO}_{3}(3 \times 2 \mathrm{~mL})$, and brine $(3 \times 2 \mathrm{~mL})$, and the organic layer was dried over $\mathrm{Na}_{2} \mathrm{SO}_{4}$ and filtered. The filtrate was concentrated and purified by silica gel column chromatography (100/1 to 50/1 DCM/MeOH) to afford compound $3(137 \mathrm{mg}, 61 \%)$ as a colorless oil: $[\alpha]_{\mathrm{D}}^{24}-150.6\left(c 0.10, \mathrm{CHCl}_{3}\right)$; IR (KBr) $v_{\max } 3446,2934,2115,1743,1636,1515,1248,1179,620,560 \mathrm{~cm}^{-1}$; ${ }^{1} \mathrm{H}$ NMR $\left(400 \mathrm{MHz}, \mathrm{CDCl}_{3}\right)$ mixture of rotamers $\delta 7.26-7.16(\mathrm{~m}, 5 \mathrm{H}), 7.12,7.09(\mathrm{~d}, J=8.5 \mathrm{~Hz}, 2 \mathrm{H}), 6.91$ $(\mathrm{d}, J=7.3 \mathrm{~Hz}, 1 \mathrm{H}), 6.85,6.80(\mathrm{~d}, J=8.6 \mathrm{~Hz}, 2 \mathrm{H}), 5.48(\mathrm{dd}, J=10.5,6.2 \mathrm{~Hz}, 1 \mathrm{H}), 5.40,4.86(\mathrm{q}, J=6.6 \mathrm{~Hz}$, $1 \mathrm{H}), 5.34,4.81(\mathrm{dd}, J=12.0,4.8 \mathrm{~Hz}, 1 \mathrm{H}), 4.73,4.62(\mathrm{p}, J=6.8 \mathrm{~Hz}, 1 \mathrm{H}), 3.77(\mathrm{~s}, 3 \mathrm{H}), 3.75,3.71(\mathrm{~s}, 3 \mathrm{H})$, 3.38-3.23 (m, 2H), 3.04-2.84 (m, 2H), 2.90, $2.89(\mathrm{~s}, 3 \mathrm{H}), 2.85,2.71(\mathrm{~s}, 3 \mathrm{H}), 2.80,2.31(\mathrm{~s}, 3 \mathrm{H}), 2.63-2.58(\mathrm{~m}$, 
$1 \mathrm{H}), 2.19-2.12(\mathrm{~m}, 2 \mathrm{H}), 1.94(\mathrm{t}, J=2.5 \mathrm{~Hz}, 1 \mathrm{H}), 1.47-1.39(\mathrm{~m}, 2 \mathrm{H}), 1.31-1.22(\mathrm{~m}, 2 \mathrm{H}), 1.21-0.96(\mathrm{~m}, 5 \mathrm{H})$, $1.18,0.80(\mathrm{~d}, J=6.7 \mathrm{~Hz}, 3 \mathrm{H}), 1.17,1.11(\mathrm{~d}, J=6.8 \mathrm{~Hz}, 3 \mathrm{H}), 1.05,1.03(\mathrm{~d}, J=6.7 \mathrm{~Hz}, 3 \mathrm{H}), 0.72,0.70(\mathrm{~d}$, $J=6.9 \mathrm{~Hz}, 3 \mathrm{H}) ;{ }^{13} \mathrm{C} \mathrm{NMR}\left(100 \mathrm{MHz}, \mathrm{CDCl}_{3}\right)$ mixture of rotamers $\delta 178.2,178.2,171.4,171.4,171.2$, 171.1, 170.8, 170.7, 169.6, 169.6, 158.8, 158.7, 137.1, 137.0, 130.3, 129.8, 129.0, 128.9, 128.5, 128.3, 126.7, $114.3,114.1,84.7,68.3,61.0,58.4,57.0,56.7,55.4,52.4,49.6,48.0,45.6,45.5,40.9,40.8,36.5,34.4,33.9$, $33.8,33.7,32.0,31.2,31.0,30.2,30.1,29.6,29.1,28.8,25.8,19.6,18.4,18.3,18.1,17.0,14.1,14.0$; HRESIMS $m / z 741.4203[\mathrm{M}+\mathrm{Na}]^{+}$(calcd. for $\mathrm{C}_{41} \mathrm{H}_{58} \mathrm{~N}_{4} \mathrm{NaO}_{7}{ }^{+}, 741.4198$ ).

(2R,4S)-N-((S)-1-(((S)-1-(((S)-1-(((S)-1-Amino-3-(4-methoxyphenyl)-1-oxopropan-2-yl)(methyl)amino)-1oxopropan-2-yl)(methyl)amino)-1-oxopropan-2-yl)amino)-1-oxo-3-phenylpropan-2-yl)-N,2,4-trimethyldec-9ynamide (carmabin A (1)) Compound $3(80.0 \mathrm{mg}, 0.111 \mathrm{mmol}$ ) was added to a sealed tube followed by anhydrous $\mathrm{NH}_{3}$ solution $(7.0 \mathrm{M}$ in $\mathrm{MeOH}, 1 \mathrm{~mL})$. After the mixture had been stirred for $20 \mathrm{~h}$ at $60^{\circ} \mathrm{C}$, the whole mixture was concentrated and purified by silica gel column chromatography (50/1 to $20 / 1 \mathrm{DCM} / \mathrm{MeOH})$ to afford a colorless oil; n-pentane $(2.5 \mathrm{~mL})$ was added, and then the mixture was stirred for $1 \mathrm{~h}$ at room temperature and filtered to afford compound $1(52.3 \mathrm{mg}, 67 \%)$ as a white powder: $[\alpha]_{\mathrm{D}}^{24}-175.6$ (c $\left.0.44, \mathrm{CHCl}_{3}\right)$; IR (KBr) $v_{\max } 3448,2935,2115,1634,1513,1249,1179,670$, $619 \mathrm{~cm}^{-1}$; HRESIMS $m / z 726.4205[\mathrm{M}+\mathrm{Na}]^{+}$(calcd. for $\mathrm{C}_{40} \mathrm{H}_{57} \mathrm{~N}_{5} \mathrm{NaO}_{6}{ }^{+}, 726.4201$ ). ${ }^{1} \mathrm{H}$ and ${ }^{13} \mathrm{C} \mathrm{NMR}$ data in the Supporting Information.

(S)-2-Methyloct-7-ynoic acid (6) To the solution of compound ent-11 (1.00 g, $2.59 \mathrm{mmol})$ in DCM (8 mL) was added TFA $(2 \mathrm{~mL})$. After the mixture had been stirred for $3 \mathrm{~h}$ at room temperature, toluene $(10 \mathrm{~mL})$ was added and then the whole mixture was concentrated under reduced pressure. The residue was dissolved with water $(10 \mathrm{~mL})$ and adjusted to $\mathrm{pH}$ 8-9 with $\mathrm{Na}_{2} \mathrm{CO}_{3}$ and extracted with $\mathrm{DCM}$ $(3 \times 20 \mathrm{~mL})$, and the combined organic layer was dried over $\mathrm{Na}_{2} \mathrm{SO}_{4}$ and filtered. The filtrate was concentrated to afford a crude oil and used directly for the next step. To the crude oil in THF (10 mL) and water $(2.5 \mathrm{~mL})$ was added $\mathrm{LiOH} \cdot \mathrm{H}_{2} \mathrm{O}(435 \mathrm{mg}, 10.4 \mathrm{mmol})$ and $\mathrm{H}_{2} \mathrm{O}_{2}(2.90 \mathrm{~mL}, 20.7 \mathrm{mmol}, 30 \%$ in water) at $0{ }^{\circ} \mathrm{C}$. After the mixture had been stirred for $3 \mathrm{~h}$ at room temperature. The whole mixture was adjusted to $\mathrm{pH} 2-3$ with $1 \mathrm{~N} \mathrm{HCl}$ and extracted with EtOAc $(3 \times 30 \mathrm{~mL})$, and the combined organic layer was dried over $\mathrm{Na}_{2} \mathrm{SO}_{4}$ and filtered. The filtrate was concentrated and purified by silica gel column chromatography (petroleum ether $/ \mathrm{EtOAc}=50 / 1-30 / 1)$ to afford compound $6(248 \mathrm{mg}, 62 \%)$ as a colorless oil: $[\alpha]_{\mathrm{D}}^{25}+13.2\left(c 0.90, \mathrm{CHCl}_{3}\right)$; IR $(\mathrm{KBr}) v_{\max } 3304,2942,2865,2118,1706,1236,638 \mathrm{~cm}^{-1}$; ${ }^{1} \mathrm{H}$ NMR $\left(400 \mathrm{MHz}, \mathrm{CDCl}_{3}\right) \delta 2.52-2.42(\mathrm{~m}, 1 \mathrm{H}), 2.20(\mathrm{td}, J=6.9,2.5 \mathrm{~Hz}, 2 \mathrm{H}), 1.94(\mathrm{t}, J=2.5 \mathrm{~Hz}, 1 \mathrm{H})$, $1.75-1.65(\mathrm{~m}, 1 \mathrm{H}), 1.58-1.42(\mathrm{~m}, 5 \mathrm{H}), 1.19(\mathrm{~d}, J=7.0 \mathrm{~Hz}, 3 \mathrm{H}) ;{ }^{13} \mathrm{C} \mathrm{NMR}\left(100 \mathrm{MHz}, \mathrm{CDCl}_{3}\right) \delta 182.9$, 84.4, 68.5, 39.3, 33.1, 28.4, 26.4, 18.4, 17.0; compound 6 was not observed by HRESIMS analysis due to complete fragmentation.

(R)-2-methyloct-7-ynoic acid (ent-6) Compound ent-6 was obtained from compound 11 (800 mg, $2.07 \mathrm{mmol})$ following the same procedure for the preparation of compound $6(200 \mathrm{mg}, 63 \%)$ colorless oil: $[\alpha]_{\mathrm{D}}^{25}-13.0\left(\mathrm{c} 0.90, \mathrm{CHCl}_{3}\right) ;{ }^{1} \mathrm{H}$ NMR $\left(400 \mathrm{MHz}, \mathrm{CDCl}_{3}\right) \delta 2.52-2.43(\mathrm{~m}, 1 \mathrm{H}), 2.20(\mathrm{td}, J=6.9$, $2.5 \mathrm{~Hz}, 2 \mathrm{H}), 1.94(\mathrm{t}, J=2.5 \mathrm{~Hz}, 1 \mathrm{H}), 1.74-1.65(\mathrm{~m}, 1 \mathrm{H}), 1.58-1.42(\mathrm{~m}, 5 \mathrm{H}), 1.19(\mathrm{~d}, J=7.0 \mathrm{~Hz}, 3 \mathrm{H})$. The spectroscopic data are in agreement with those reported in the literature [9].

Methyl(2S,5S,8S,11S,14S)-11-benzyl-2-(4-methoxybenzyl)-3,5,6,8,12,14-hexamethyl-4,7,10,13-tetraoxo-3, 6,9,12-tetraazaicos-19-ynoate (4) Compound 4 was obtained from compound 7 ( $200 \mathrm{mg}, 0.312 \mathrm{mmol}$ ) and compound 6 ( $95.9 \mathrm{mg}, 0.622 \mathrm{mmol}$ ) following the procedure for the preparation of compound 3 , (116 mg, 55\%), colorless oil: $[\alpha]_{\mathrm{D}}^{24}-59.8\left(c 0.10, \mathrm{CHCl}_{3}\right)$; IR (KBr) $v_{\max } 3444,2935,2115,1744,1642$, $1515,1248,1179,701,618 \mathrm{~cm}^{-1} ;{ }^{1} \mathrm{H}$ NMR $\left(400 \mathrm{MHz}, \mathrm{CDCl}_{3}\right)$ mixture of rotamers $\delta 7.27-7.14(\mathrm{~m}, 5 \mathrm{H})$, $7.12,7.09(\mathrm{~d}, J=8.9 \mathrm{~Hz}, 2 \mathrm{H}), 6.94(\mathrm{~d}, J=7.2 \mathrm{~Hz}, 1 \mathrm{H}), 6.86,6.80(\mathrm{~d}, J=8.6 \mathrm{~Hz}, 2 \mathrm{H}), 5.47(\mathrm{dd}, J=10.1$, $6.2 \mathrm{~Hz}, 1 \mathrm{H}), 5.41,4.84(\mathrm{dd}, J=12.9,6.2 \mathrm{~Hz}, 1 \mathrm{H}), 5.33,4.76(\mathrm{dd}, J=12.1,7.3 \mathrm{~Hz}, 1 \mathrm{H}), 4.73,4.62(\mathrm{p}$, $J=6.9 \mathrm{~Hz}, 1 \mathrm{H}), 3.77(\mathrm{~s}, 3 \mathrm{H}), 3.75,3.72(\mathrm{~s}, 3 \mathrm{H}), 3.39-3.24(\mathrm{~m}, 2 \mathrm{H}), 3.02-2.91(\mathrm{~m}, 2 \mathrm{H}), 2.90,2.89(\mathrm{~s}, 3 \mathrm{H})$, 2.85, 2.78, $2.71(\mathrm{~s}, 3 \mathrm{H}), 2.80,2.34,2.31(\mathrm{~s}, 3 \mathrm{H}), 2.60-2.52(\mathrm{~m}, 1 \mathrm{H}), 2.20-2.13(\mathrm{~m}, 2 \mathrm{H}), 1.94-1.91(\mathrm{~m}, 1 \mathrm{H})$, $1.72-1.64(\mathrm{~m}, 1 \mathrm{H}), 1.53-1.47(\mathrm{~m}, 2 \mathrm{H}), 1.40-1.30(\mathrm{~m}, 3 \mathrm{H}), 1.18,1.10,0.81(\mathrm{~d}, J=6.7 \mathrm{~Hz}, 3 \mathrm{H}), 1.18,1.11$, 
$1.05(\mathrm{~d}, J=6.8 \mathrm{~Hz}, 3 \mathrm{H}), 0.79(\mathrm{~d}, J=6.8 \mathrm{~Hz}, 3 \mathrm{H}) ;{ }^{13} \mathrm{C} \mathrm{NMR}\left(100 \mathrm{MHz}, \mathrm{CDCl}_{3}\right)$ mixture of rotamers $\delta$ 177.7, 177.6, 171.4, 171.3, 171.1, 170.9, 170.7, 170.5, 169.4, 169.4, 168.4, 158.7, 158.6, 137.4, 137.0, 136.9, 130.1, 129.7, 129.6, 129.1, 128.8, 128.7, 128.3, 128.1, 127.0, 126.5, 114.2, 114.0, 113.9, 84.4, 84.3, 68.5, 68.3, $68.2,62.9,60.9,58.2,56.9,56.8,55.3,55.2,52.4,52.3,49.5,47.9,45.8,45.5,45.3,35.8,35.4,34.5,34.3,33.7$, $33.6,33.3,33.2,32.9,31.9,31.3,31.2,30.0,29.6,29.5,29.0,28.5,28.4,26.7,26.6,26.2,18.2,18.1,18.0,17.3$, 14.0, 13.9; HRESIMS $m / z$ 699.3732 [M + Na] ${ }^{+}$(calcd. for $\mathrm{C}_{38} \mathrm{H}_{52} \mathrm{~N}_{4} \mathrm{NaO}_{7}{ }^{+}, 699.3728$.

(S)-N-((S)-1-(((S)-1-(((S)-1-(((S)-1-Amino-3-(4-methoxyphenyl)-1-oxopropan-2-yl)(methyl)amino)-1-oxopropan2-yl)(methyl)amino)-1-oxopropan-2-yl)amino)-1-oxo-3-phenylpropan-2-yl)-N,2-dimethyloct-7-ynamide (2) Compound 2 was obtained from compound $4(80.0 \mathrm{mg}, 0.118 \mathrm{mmol})$ following the procedure for the preparation of compound $1,(47.7 \mathrm{mg}, 61 \%)$, white powder: $[\alpha]_{\mathrm{D}}^{25}-163.8\left(c 0.50, \mathrm{CHCl}_{3}\right)$; IR $(\mathrm{KBr})$ $v_{\max } 3447,2935,2114,1634,1514,1249,1081,700,617$; HRESIMS $m / z 684.3736$ [M + Na] ${ }^{+}$(calcd. for $\mathrm{C}_{37} \mathrm{H}_{51} \mathrm{~N}_{5} \mathrm{NaO}_{6}{ }^{+}$, 684.3732). ${ }^{1} \mathrm{H}$ and ${ }^{13} \mathrm{C}$ NMR data are in the Supplementary Materials.

Methyl (2S,5S,8S,11S,14R)-11-benzyl-2-(4-methoxybenzyl)-3,5,6,8,12,14-hexamethyl-4,7,10,13-tetraoxo-3, 6,9,12-tetraazaicos-19-ynoate (4a) Compound 4a was obtained from compound 7 ( $200 \mathrm{mg}, 0.312 \mathrm{mmol}$ ) and compound ent-6 $(95.9 \mathrm{mg}, 0.622 \mathrm{mmol})$ following the procedure for the preparation of compound 3, (108 mg, 51\%), colorless oil: $[\alpha]_{\mathrm{D}}^{23}-105.0\left(c 0.10, \mathrm{CHCl}_{3}\right)$; IR (KBr) $v_{\max } 3447,2931,2115,1636,1385$, $1271,1179,670,615 \mathrm{~cm}^{-1} ;{ }^{1} \mathrm{H}$ NMR $\left(400 \mathrm{MHz}, \mathrm{CDCl}_{3}\right)$ mixture of rotamers $\delta$ 7.27-7.16 (m, 5H), 7.12, $7.09(\mathrm{~d}, J=8.7 \mathrm{~Hz}, 2 \mathrm{H}), 6.91(\mathrm{~d}, J=7.1 \mathrm{~Hz}, 1 \mathrm{H}), 6.85,6.80(\mathrm{~d}, J=8.7 \mathrm{~Hz}, 2 \mathrm{H}), 5.45(\mathrm{dd}, J=10.1,6.2 \mathrm{~Hz}$, $1 \mathrm{H}), 5.40,4.83(\mathrm{dd}, J=12.9,6.4 \mathrm{~Hz}, 1 \mathrm{H}), 5.34,4.76(\mathrm{dd}, J=11.9,4.8 \mathrm{~Hz}, 1 \mathrm{H}), 4.73,4.62(\mathrm{p}, J=6.9 \mathrm{~Hz}$, $1 \mathrm{H}), 3.77(\mathrm{~s}, 3 \mathrm{H}), 3.75,3.72(\mathrm{~s}, 3 \mathrm{H}), 3.38-3.26(\mathrm{~m}, 2 \mathrm{H}), 3.05-2.92(\mathrm{~m}, 2 \mathrm{H}), 2.91,2.89(\mathrm{~s}, 3 \mathrm{H}), 2.85,2.77,2.71$ $(\mathrm{s}, 3 \mathrm{H}), 2.81,2.34,2.31(\mathrm{~s}, 3 \mathrm{H}), 2.55-2.50(\mathrm{~m}, 1 \mathrm{H}), 2.08-2.03(\mathrm{~m}, 2 \mathrm{H}), 1.94-1.91(\mathrm{~m}, 1 \mathrm{H}), 1.49-1.41(\mathrm{~m}$, $1 \mathrm{H}), 1.39-1.31(\mathrm{~m}, 2 \mathrm{H}), 1.21-1.06(\mathrm{~m}, 3 \mathrm{H}), 1.19,1.10,0.81(\mathrm{~d}, J=6.8 \mathrm{~Hz}, 3 \mathrm{H}), 1.17,1.11,(\mathrm{~d}, J=6.8 \mathrm{~Hz}$, $3 \mathrm{H}), 1.07,0.44(\mathrm{~d}, J=6.7 \mathrm{~Hz}, 3 \mathrm{H}) ;{ }^{13} \mathrm{C}$ NMR $\left(100 \mathrm{MHz}, \mathrm{CDCl}_{3}\right)$ mixture of rotamers $\delta 177.7,177.6,171.4$, 171.2, 171.0, 170.8, 170.6, 169.5, 169.5, 158.8, 158.7, 137.5, 137.2, 137.1, 130.2, 129.8, 129.2, 128.9, 128.8, $128.5,126.6,114.3,114.1,84.5,68.3,63.2,61.0,58.4,57.2,56.8,55.3,52.4,52.4,49.6,47.9,45.5,45.4,36.0$ 34.4, 33.7, 33.7, 33.3, 32.0, 31.4, 31.1, 30.1, 29.6, 29.1, 28.5, 26.3, 18.3, 18.2, 18.1, 17.4, 17.4, 14.1, 14.0; HRESIMS $m / z$ 699.3732 [M + Na] ${ }^{+}$(calcd. for $\mathrm{C}_{38} \mathrm{H}_{52} \mathrm{~N}_{4} \mathrm{NaO}_{7}{ }^{+}$, 699.3728).

(R)-N-((S)-1-(((S)-1-(((S)-1-(((S)-1-Amino-3-(4-methoxyphenyl)-1-oxopropan-2-yl)(methyl)amino)-1-oxopropan2-yl)(methyl)amino)-1-oxopropan-2-yl)amino)-1-oxo-3-phenylpropan-2-yl)-N,2-dimethyloct-7-ynamide (dragomabin (2a)) Compound 2a was obtained from compound $4 \mathbf{a}(80.0 \mathrm{mg}, 0.118 \mathrm{mmol})$ following the procedure for the preparation of compound $1,(43.8 \mathrm{mg}, 56 \%)$, white powder: $[\alpha]_{\mathrm{D}}^{25}-118.3\left(c 0.50, \mathrm{CHCl}_{3}\right)$; IR $(\mathrm{KBr}) v_{\max } 3448$, 2936, 2114, 1636, 1515, 1249, 1179, 668, 616; HRESIMS $m / z$ 684.3736 [M + Na] ${ }^{+}$(calcd. for $\mathrm{C}_{37} \mathrm{H}_{51} \mathrm{~N}_{5} \mathrm{NaO}_{6}{ }^{+}$, 684.3732). ${ }^{1} \mathrm{H}$ and ${ }^{13} \mathrm{C}$ NMR data are in the Supplementary Materials.

\section{Conclusions}

In summary, carmabin A and dragomabin have been synthesized in an efficient and stereoselective fashion (52.3 mg and $43.8 \mathrm{mg}$ obtained, respectively). The absolute stereochemistry at C35 and C37 of carmabin A has been assigned as $35 R, 37 S$ and the absolute stereochemistry at C35 of dragomabin has been revised as $35 R$. It is anticipated that this work will lead to further investigations of carmabin $\mathrm{A}$ and dragomabin as well as other acetylene-containing lipopeptides in both medicinal chemistry and chemical biology.

Supplementary Materials: The following are available online at http:/ / www.mdpi.com/1660-3397/16/9/338/s1, Figures S1-S3: NMR comparison of natural and synthetic carmabin A (1), Figures S4-S6: NMR comparison of natural and synthetic dragomabin (2a), Figures S7-S64: NMR, COSYS, HSQC, NOESY and HMBC Spectra, Tables S1 and S2: NMR data of natural and synthetic carmabin A (1); Tables S3 and S4: NMR data of natural and synthetic dragomabin (2a).

Author Contributions: Y.C., L.W., and B.Y. conceived and designed the experiments; B.Y., P.J., and T.Z. performed the experiments; Y.S., Y.J.C., and X.H. helped with data collection and analyses; L.W. and B.Y. wrote the paper. 
Funding: We acknowledge financial support from Fundamental Research Funds for the Central Universities, the National Natural Science Foundation of China (NSFC) (81573282 to Y.C. and 81703350 to L.W.), the National Science Fund for Distinguished Young Scholars (81625021 to Y.C.), and the Hundred Young Academic Leaders Program of Nankai University.

Conflicts of Interest: The authors declare no conflict of interest. The founding sponsors had no role in the design of the study; in the collection, analyses, or interpretation of data; in the writing of the manuscript; or the decision to publish the results.

\section{References}

1. Costa, M.; Costa-Rodrigues, J.; Fernandes, M.H.; Barros, P.; Vasconcelos, V.; Martins, R. Marine cyanobacteria compounds with anticancer properties: A review on the implication of apoptosis. Mar. Drugs 2012, 10, 2181-2207. [CrossRef] [PubMed]

2. Blunt, J.W.; Copp, B.R.; Keyzers, R.A.; Munro, M.H.; Prinsep, M.R. Marine natural products. Nat. Prod. Rep. 2015, 32, 116-211. [CrossRef] [PubMed]

3. Sarvesh, S.R.; Tabassum, K. Novel anti-inflammatory drugs from marine microbes. Nat. Prod. J. 2015, 5, 206-218.

4. Jo, C.; Khan, F.F.; Khan, M.I.; Iqbal, J. Marine bioactive peptides: Types, structures, and physiological functions. Food Rev. Int. 2017, 33, 44-61. [CrossRef]

5. Silipo, A.; Molinaro, A.; Molteni, M.; Rossetti, C.; Parrilli, M.; Lanzetta, R. Full structural characterization of an extracellular polysaccharide produced by the freshwater cyanobacterium oscillatoria planktothrix fp1. Eur. J. Org. Chem. 2010, 2010, 5594-5600. [CrossRef]

6. Mazard, S.; Penesyan, A.; Ostrowski, M.; Paulsen, I.T.; Egan, S. Tiny microbes with a big impact: The role of cyanobacteria and their metabolites in shaping our future. Mar. Drugs 2016, 14, 97. [CrossRef] [PubMed]

7. Yamaguchi, M.; Park, H.J.; Ishizuka, S.; Omata, K.; Hirama, M. Chemistry and antimicrobial activity of caryoynencins analogs. J. Med. Chem. 1995, 38, 5015-5022. [CrossRef] [PubMed]

8. Xu, Z.S.; Peng, Y.G.; Ye, T. The total synthesis and stereochemical revision of yanucamide A. Org. Lett. 2003, 5, 2821-2824. [CrossRef] [PubMed]

9. Chen, H.L.; Feng, Y.Q.; Xu, Z.S.; Ye, T. The total syntheses and reassignment of stereochemistry of dragonamide. Tetrahedron 2005, 61, 11132-11140. [CrossRef]

10. Okamoto, S.; Iwasaki, A.; Ohno, O.; Suenaga, K. Isolation and structure of kurahyne B and total synthesis of the kurahynes. J. Nat. Prod. 2015, 78, 2719-2725. [CrossRef] [PubMed]

11. Iwasaki, A.; Fujimura, H.; Okamoto, S.; Kudo, T.; Hoshina, S.; Sumimoto, S.; Teruya, T.; Suenaga, K. Isolation of jahanene and jahanane, and total synthesis of the jahanyne family. J. Org. Chem. 2018, 83, 9592-9603. [CrossRef] [PubMed]

12. Kallepu, S.; Kavitha, M.; Yeeravalli, R.; Manupati, K.; Jadav, S.S.; Das, A.; Mainkar, P.S.; Chandrasekhar, S. Total synthesis of desmethyl jahanyne and its lipo-tetrapeptide conjugates derived from parent skeleton as bcl-2-mediated apoptosis-inducing agents. ACS Omega 2018, 3, 63-75. [CrossRef] [PubMed]

13. Siow, A.; Opiyo, G.; Kavianinia, I.; Li, F.F.; Furkert, D.P.; Harris, P.W.R.; Brimble, M.A. Total synthesis of the highly N-methylated acetylene-containing anticancer peptide jahanyne. Org. Lett. 2018, 20, 788-791. [CrossRef] [PubMed]

14. Ye, B.; Jiang, P.; Zhang, T.; Ding, Y.; Sun, Y.; Hao, X.; Li, L.; Wang, L.; Chen, Y. Total synthesis of the highly N-methylated peptide jahanyne. J. Org. Chem. 2018, 83, 6741-6747. [CrossRef] [PubMed]

15. Hooper, G.J.; Orjala, J.; Schatzman, R.C.; Gerwick, W.H. Carmabins A and B, new lipopeptides from the caribbean cyanobacterium lyngbya majuscula. J. Nat. Prod. 1998, 61, 529-533. [CrossRef] [PubMed]

16. McPhail, K.L.; Correa, J.; Linington, R.G.; Gonzalez, J.; Ortega-Barria, E.; Capson, T.L.; Gerwick, W.H. Antimalarial linear lipopeptides from a panamanian strain of the marine cyanobacterium lyngbya majuscula. J. Nat. Prod. 2007, 70, 984-988. [CrossRef] [PubMed]

17. Evans, D.A.; Takacs, J.M. Enantioselective alkylation of chiral enolates. Tetrahedron Lett. 1980, 21, 4233-4236. [CrossRef]

18. Evans, D.A.; Ennis, M.D.; Mathre, D.J. Asymmetric alkylation reactions of chiral imide enolates. A practical approach to the enantioselective synthesis of .alpha.-substituted carboxylic acid derivatives. J. Am. Chem. Soc. 1982, 104, 1737-1739. [CrossRef] 
19. De Joarder, D.; Jennings, M.P. Convergent enantioselective syntheses of two potential $C_{25}-C_{40}$ subunits of (-)-caylobolide A. Tetrahedron Lett. 2011, 52, 5124-5127.

20. Silvi, M.; Arceo, E.; Jurberg, I.D.; Cassani, C.; Melchiorre, P. Enantioselective organocatalytic alkylation of aldehydes and enals driven by the direct photoexcitation of enamines. J. Am. Chem. Soc. 2015, 137, 6120-6123. [CrossRef] [PubMed]

21. Carpino, L.A. 1-hydroxy-7-azabenzotriazole. An efficient peptide coupling additive. J. Am. Chem. Soc. 1993, 115, 4397-4398. [CrossRef]

22. Stasiak, M.; Slomczynska, U.; Olma, A.; Leplawy, M.T. Chemistry of alpha-hydroxymethylserine: Problems and solutions. J. Pept. Sci. 2008, 14, 1163-1172. [CrossRef] [PubMed]

23. Nabika, R.; Oishi, S.; Misu, R.; Ohno, H.; Fujii, N. Synthesis of ib-01212 by multiple N-methylations of peptide bonds. Bioorg. Med. Chem. 2014, 22, 6156-6162. [CrossRef] [PubMed]

2018 by the authors. Licensee MDPI, Basel, Switzerland. This article is an open access article distributed under the terms and conditions of the Creative Commons Attribution (CC BY) license (http://creativecommons.org/licenses/by/4.0/). 